\title{
Hygiene
}

\section{Bohrerständer aus Medical-Kunststoff}

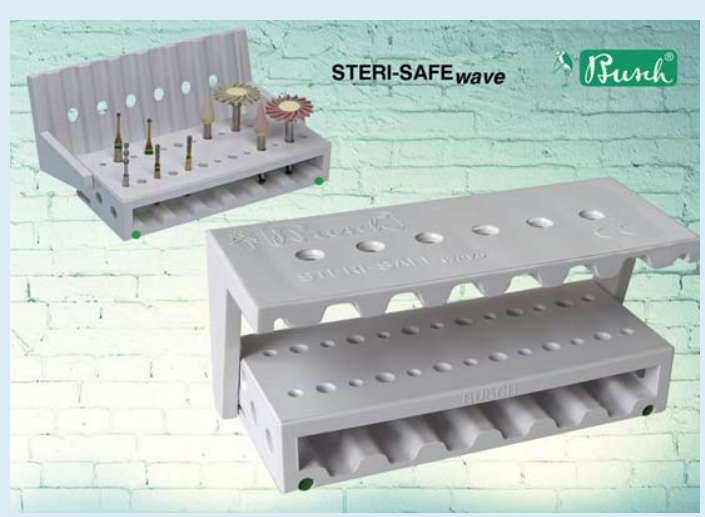

Der neue BUSCH STERI-SAFEwave Bohrerständer aus Medical-Kunststoff überzeugt in Anwendung, Sicherheit und Hygiene. Die kombinierte Aufnahmekapazität von FG- und WST-Instrumenten ist ein wesentlicher Vorteil und eine besondere Innovation dieses Bohrerständers. Die wave-Konstruktion mit unterschiedlichen Einsteckhöhen macht es möglich. Beim Transport und während der Wieder- aufbereitung ist der Sicherungsbügel in geschlossenem Zustand arretiert und sichert das kombinierte Instrumentarium gegen Herausfallen. Der desinfizierbare und sterilisierbare MedicalKunststoff ist zudem für alle praxisrelevanten Wiederaufbereitungsmaßnahmen geeignet. Die offene Konstruktion unterstützt eine bessere Durchströmung im Sinne einer optimalen und effektiven Wiederaufbereitung. Aufgrund seiner kompakten Abmessung lässt sich der Ständer in bestehende Hygienekonzepte einbinden (Sterilgutverpackung/-Container). Die Reinigungsfähigkeit inkl. vorkontaminierter Medizinprodukte wurde durch ein externes Institut validiert und dokumentiert.

Nach einer Pressemitteilung der Busch \& Co. GmbH \& Co. KG, Engelskirchen www.busch-dentalshop.de. 